\title{
The clinical significance of sperm DNA damage detection combined with routine semen testing in assisted reproduction
}

\author{
YAN ZHANG $^{2 *}$, HUI WANG $^{1 *}$, LIRONG WANG $^{1}$, ZUOMIN ZHOU $^{1}$, JIAHAO SHA $^{1}$, YUNDONG MAO $^{2}$, \\ LINGBO CAI $^{2}$, TING FENG ${ }^{2}$, ZHENGJIE YAN ${ }^{2}$, LONG MA $^{2}$ and JIAYIN LIU ${ }^{1,2}$ \\ ${ }^{1}$ Laboratory of Reproductive Medicine, Nanjing Medical University; ${ }^{2}$ Center of Clinical Reproductive Medicine, Department \\ of Obstetrics and Gynecology, The First Affiliated Hospital of Nanjing Medical University, Nanjing 210029, P.R. China
}

Received June 4, 2008; Accepted July 22, 2008

DOI: 10.3892/mmr_00000002

\begin{abstract}
Traditional routine semen analysis and biochemical assays are insufficient for the determination of fertility status in individual men. In recent years, clinical evidence has shown that damaged human sperm DNA may adversely affect assisted reproductive outcomes and that the spermatozoa of infertile men possess substantially more DNA damage than the spermatozoa of fertile men. In this study, we combined these two methods to test their clinical significance in assisted reproductive techniques (ART). A total of 302 in vitro fertilization (IVF) and 67 intracytoplasmic sperm injection (ICSI) couples were included in the study. The acridine orange technique (AOT) was used to detect the DNA integrity of the sperm. Correlation analysis showed that the DNA fragmentation index (DFI) was negatively related to the no. of good quality embryos and the clinical pregnancy rate in IVF patients. No significant correlations were found between DFI and ICSI patients. We then combined the results of the routine semen testing of IVF patients with their DFI values. Statistical analysis revealed notable differences in the no. of good quality embryos $(\mathrm{P}=0.015)$ and the clinical pregnancy rate $(\mathrm{P}=0.015)$ between subgroups divided according to DFI value in a group with normal semen test results (Group 1). In a group with abnormal semen test results (Group 2), the fertilization rate $(\mathrm{P}=0.034)$ and the pregnancy rate $(\mathrm{P}=0.018)$ showed remarkable variation between DFI subgroups. In conclusion, the detection of damaged DNA in spermatozoa needs to be conducted along with standard semen analysis. This might prove to be a promising predictor of ART outcome, particularly in IVF.
\end{abstract}

Correspondence to: Dr Jiaying Liu, Laboratory of Reproductive Medicine, Nanjing Medical University and Center of Clinical Reproductive Medicine, Department of Obstetrics and Gynecology, The First Affiliated Hospital of Nanjing Medical University, Nanjing 210029, P.R. China

E-mail: jyliu_nj@126.com

${ }^{*}$ Contributed equally

Key words: sperm DNA damage, acridine orange technique, semen analysis, assisted reproductive technology, prediction

\section{Introduction}

Traditionally, the diagnosis of male infertility has relied on microscopic assessment and biochemical assay for the determination of human semen quality. The conventional parameters that have been considered the most important are the concentration, motility and morphology of sperm in the ejaculate (1). However, there is little consensus as to which of these parameters within conventional semen analysis is the best predictor of poor fertility, and recently conflicting conclusions have been drawn in different studies (2).

It has therefore become apparent that basic semen analysis is insufficient for the determination of the fertility status of individual men. New markers are needed to better discriminate infertile from fertile men and to predict pregnancy outcome and the risk of adverse reproductive events (3). Among the tests showing the most promise in predicting the successful treatment of male infertility patients are those measuring sperm DNA quality (4). The normality of sperm nuclear chromatin DNA plays a critical role in human fertilization and subsequent embryonic development. In recent years, there have been many reports on the relationship between fertilization and pregnancy rates in clinical assisted reproductive techniques (ART) and on sperm DNA normality detected by various methods, including acridine orange (AO) fluorescence staining assessed by microscopy, flow cytometry using the sperm chromatin structure assay (SCSA), terminal deoxynucleotidyl transferase-mediated dUTP nick-end labeling (TUNEL) and electrophoresis (comet assays) $(5,6)$.

The acridine orange technique (AOT) uses fluorescence staining to distinguish sperm with either double- (green fluorescence) or single- (denatured, red fluorescence) stranded DNA. It has been used to evaluate relationships between abnormal sperm DNA detected by AO and adverse outcomes in both in vitro fertilization (IVF) and intracytoplasmic sperm injection (ICSI), such as lower implantation rates and higher pregnancy loss. It has even been suggested that abnormal sperm DNA may affect offspring (7-9).

Although semen analysis of the male infertile patient still provides the fundamental information at initial diagnosis, researchers are attempting to develop other male 'fertility' predictors. In the present study, we combined routine semen analysis and the AO test to evaluate human fertility in this era of assisted reproduction. The objectives of this study were: 
Table I. Clinical characteristics of semen samples from in vitro fertilization and intracytoplasmic sperm injection patients.

\begin{tabular}{|c|c|c|c|c|c|c|c|}
\hline \multirow[b]{3}{*}{ Subgroup } & \multicolumn{6}{|c|}{ IVF } & \multirow[t]{3}{*}{ ICSI } \\
\hline & \multicolumn{3}{|c|}{ Group 1 (normal) } & \multicolumn{3}{|c|}{ Group 2 (abnormal) } & \\
\hline & A & $\mathrm{B}$ & $\mathrm{C}$ & A & $\mathrm{B}$ & $\mathrm{C}$ & \\
\hline No. of subjects & 99 & 82 & 19 & 40 & 50 & 12 & 67 \\
\hline $\begin{array}{l}\text { Volume of } \\
\text { ejaculate (ml) }\end{array}$ & $3.2 \pm 1.06$ & $3.6 \pm 1.44$ & $3.7 \pm 1.48$ & $3.06 \pm 1.24$ & $3.9 \pm 1.75$ & $3.2 \pm 1.6$ & $4 \pm 1.1$ \\
\hline $\begin{array}{l}\text { Liquefaction } \\
\text { time (min) }\end{array}$ & $28.78 \pm 5.25$ & $27.53 \pm 6.37$ & $29.74 \pm 4.13$ & $36.25 \pm 21.29$ & $33 \pm 19.3$ & $35.83 \pm 21.78$ & $31.67 \pm 12.67$ \\
\hline $\mathrm{pH}$ & $7.39 \pm 0.06$ & $7.38 \pm 0.07$ & $7.39 \pm 0.08$ & $7.39 \pm 0.08$ & $7.38 \pm 0.06$ & $7.43 \pm 0.06$ & $7.4 \pm 0.06$ \\
\hline Viability (\%) & $74.51 \pm 9.17$ & $72.95 \pm 10.8$ & $75.74 \pm 8.96$ & $43.32 \pm 10.44$ & $41.24 \pm 11.72$ & $39.5 \pm 12.83$ & $36.72 \pm 27.32$ \\
\hline Motility (\%) & $62.84 \pm 9.44$ & $61.1 \pm 10.8$ & $61.32 \pm 11.06$ & $33.68 \pm 9.19$ & $33.52 \pm 10.1$ & $27.83 \pm 14.47$ & $28.7 \pm 22.72$ \\
\hline $\begin{array}{l}\text { Sperm count } \\
\left(\mathrm{x} 10^{6} / \mathrm{ml}\right)\end{array}$ & $62.43 \pm 37.27$ & $53.03 \pm 29.67$ & $54.48 \pm 44.65$ & $57.69 \pm 39.90$ & $44.35 \pm 29.48$ & $41.06 \pm 53.29$ & $29.99 \pm 37.29$ \\
\hline $\begin{array}{l}\text { Morphology } \\
\text { (\% abnormal) }\end{array}$ & $<30$ & $<30$ & $<30$ & $33.86 \pm 11.43$ & $36.8 \pm 13.96$ & $39.58 \pm 13.46$ & $44.25 \pm 18.93$ \\
\hline DFI value (\%) & $2 \pm 0.78$ & $5.7 \pm 1.7$ & $14 \pm 3.79$ & $1.92 \pm 0.84$ & $6.1 \pm 1.59$ & $16.76 \pm 4.24$ & $9 \pm 6.29$ \\
\hline
\end{tabular}

Semen samples taken from in vitro fertilization (IVF) male patients were characterized according to the 1999 WHO criteria and divided into normal (Group 1) or abnormal (Group 2) sperm DNA groups. Each of the two groups was further divided into subgroups according to the DNA fragmentation index (DFI): subgroup A, DFI <4\%; subgroup B, DFI 4-10\%; subgroup C, DFI >10\%. Intracytoplasmic sperm injection (ICSI) patients were not divided into subgroups due to their limited nos.

i) to explore the relationship between sperm DNA normality evaluated according to the DNA fragmentation index (DFI) and fertilization, blastocyst development, and ongoing pregnancies in IVF ( $n=302)$ and ICSI ( $n=67)$ patients, and ii) to combine our findings with the results of semen analysis, separating IVF couples into normal and abnormal groups and surveying certain consequences of the IVF process in the two. The purpose of this analysis was to evaluate the diagnostic value of assessing DFI values along with routine semen results in ART.

\section{Materials and methods}

Patients. The study was conducted at the Laboratory of Reproductive Medicine, Nanjing Medical University and the Human Clinical Reproductive Medicine Center, The First Affiliated Hospital of Nanjing Medical University. A total of 369 (302 with IVF and 67 with ICSI) couples treated with ART and blastocyst transfer were prospectively evaluated. Routine semen analysis using the computer-assisted sperm analysis (CASA) system (WLJY-9000, Beijing Weili New Century Science and Tech Dev. Co., Ltd., China) was performed after semen liquefaction according to the WHO manual (World Health Organization, 1999). All patients signed institutionally approved forms providing informed consent for their treatment. According to the results of routine semen analysis, male partners in 302 IVF couples were separated into two groups: Group 1, males with normal semen parameters, and Group 2, males with abnormal semen parameters.

Sperm preparation and acridine orange testing. Semen samples were allowed to liquefy at room temperature, and then were washed three times in phosphate-buffered saline $(0.1 \mathrm{M}$ PBS). After centrifugation, the sperm pellet was resuspended to about $50 \times 10^{6} / \mathrm{ml}$. A small aliquot $(15 \mu \mathrm{l})$ of sperm suspension was smeared on a glass slide. The normality of sperm chromatin DNA was assessed using the AO (Sigma Chemicals Co., St. Louis, MO, USA) fluorescence method as previously described (10). In brief, after air-drying the sperm slides were fixed in Carnoy's solution (methanol/acetic acid, 3:1) for at least $3 \mathrm{~h}$ or overnight. Once rinsed and air dried, they were stained for 5 min with AO staining solution, prepared daily as follows: $10 \mathrm{ml}$ of $1 \% \mathrm{AO}$ stock solution in distilled water added to a mixture of $40 \mathrm{ml}$ of $0.1 \mathrm{M}$ citric acid and $2.5 \mathrm{ml}$ of $0.3 \mathrm{M} \mathrm{Na}_{2} \mathrm{HPO}_{4} 7 \mathrm{H}_{2} \mathrm{O}, \mathrm{pH} 2.5$. The $1 \% \mathrm{AO}$ stock solution was stored in the dark at $4^{\circ} \mathrm{C}$ for 4 weeks, then the slides were gently rinsed and mounted with distilled water. The percentage of sperm with normal DNA was calculated by scoring at least 200 sperm under a fluorescence microscope (Axioskop 2 plus, Carl Zeiss, Thornwood, NY, USA) at x400 magnification and an excitation of 450-490 nm. Sperm with normal (doublestranded) DNA were stained with green fluorescence, and those with denatured or single-stranded DNA were stained red, 

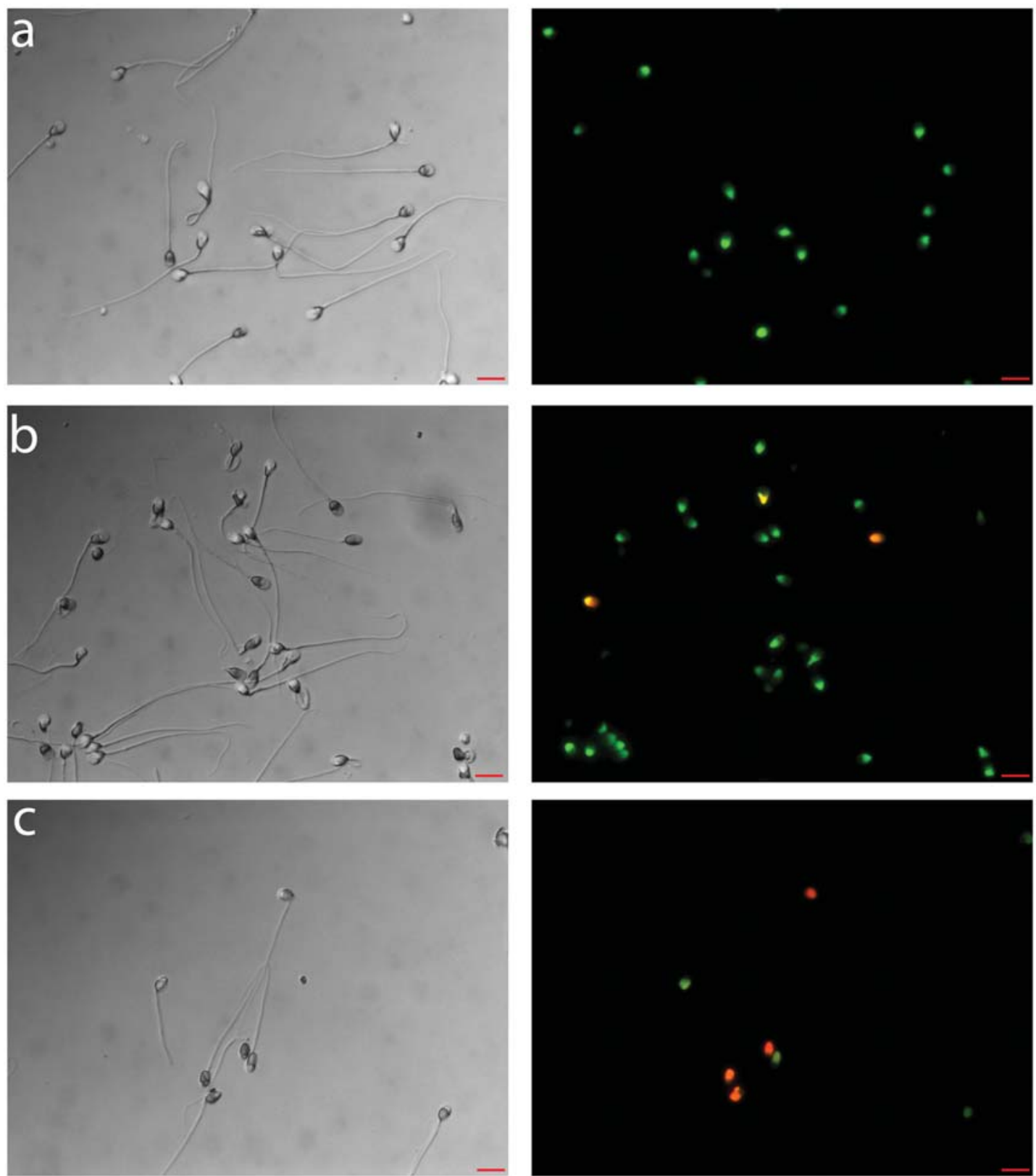

Figure 1. Acridine orange fluorescence imaging of representatives from each of the in vitro fertilization subgroups. Images were taken from patients with a DFI of (a) $<4 \%$ (subgroup A); (b) 4-10\% (subgroup B); (c) >10\% (subgroup C). Left, bright-field image; right, fluorescence image. Magnification, x1000; scale, $10 \mu \mathrm{m}$.

orange or yellow. The DFI was used to represent the ratio of spermatozoa with red, orange or yellow fluorescence to all the spermatozoa counted per percentage of sample.

Assisted reproductive techniques. Before IVF and ICSI, the female patients underwent routine controlled ovarian hyperstimulation. Follicle developments were monitored by transvaginal ultrasonography (TVUS). Egg retrieval was undertaken $36-38 \mathrm{~h}$ after HCG administration, and all oocytes were inseminated or (in ICSI patients) injected $4 \mathrm{~h}$ later. Fertilization checks were carried out 16-18 h post-insemination/injection. The no. of embryos cleaved (\%) and the no. of good quality embryos (\%) were calculated after 2-3 days. Embryo transfer (ET) was performed on day 3 after fertilization, and a pregnancy test was carried out on day 15-18 after ET and classified as positive when the serum B-HCG level was over 5 IU/l. All women with a positive result were examined by early TVUS at
4 weeks after embryo transfer to confirm the clinical pregnancy (11).

Statistical analysis. For statistical analysis, the SPSS 13.0 program (SPSS Inc., Chicago, IL, USA) was used. The significance of the correlations between the DFI (\%) and the fertilization rate $(\%)$, no. of embryos cleaved $(\%)$, no. of good quality embryos $(\%)$, no. of harvested oocytes, clinical pregnancy rate $(\%)$, female age and male age was examined by Spearman rank correlation testing. All the percentage nos. underwent arcsine transformation and square root changing. Due to the different treatments used, data from the IVF and ICSI couples were processed separately. After correlation analysis, the independent samples $\mathrm{T}$ test [for fertilization rate $(\%)$, no. of embryos cleaved (\%) and no. of good quality embryos (\%)] and cross tabulation (for clinical pregnancy rate only) were used to analyze whether there were any significant 
Table II. Correlations between the DNA fragmentation index and various factors in in vitro fertilization patients.

\begin{tabular}{|c|c|c|c|c|c|c|c|c|}
\hline & DFI & $\begin{array}{l}\text { Fertilization } \\
\text { rate }\end{array}$ & $\begin{array}{l}\text { No. of } \\
\text { embryos } \\
\text { cleaved }\end{array}$ & $\begin{array}{l}\text { No. of } \\
\text { good } \\
\text { embryos }\end{array}$ & $\begin{array}{l}\text { No. of } \\
\text { oocytes }\end{array}$ & $\begin{array}{c}\text { Clinical } \\
\text { pregnancy }\end{array}$ & $\begin{array}{l}\text { Female } \\
\text { age }\end{array}$ & $\begin{array}{c}\text { Male } \\
\text { age }\end{array}$ \\
\hline \multicolumn{9}{|l|}{ DFI } \\
\hline Pearson correlation & 1.00 & -0.09 & -0.04 & -0.12 & 0.01 & -0.15 & 0.03 & -0.06 \\
\hline Sig. (two-tailed) & & 0.10 & 0.47 & $0.04^{\mathrm{a}}$ & 0.85 & $0.01^{\mathrm{b}}$ & 0.64 & 0.33 \\
\hline \multicolumn{9}{|l|}{ Fertilization rate } \\
\hline Pearson correlation & -0.09 & 1.00 & 0.05 & 0.03 & -0.15 & -0.03 & 0.11 & 0.04 \\
\hline Sig. (two-tailed) & 0.10 & & 10.37 & 0.57 & 0.01 & 0.59 & 0.06 & 0.46 \\
\hline \multicolumn{9}{|l|}{ No. of embryos cleaved } \\
\hline Pearson correlation & -0.04 & 0.05 & 1.00 & 0.20 & -0.20 & 0.08 & 0.12 & 0.08 \\
\hline Sig. (two-tailed) & 0.47 & 0.37 & & 30.00 & 0.00 & 0.16 & 0.04 & 0.17 \\
\hline \multicolumn{9}{|l|}{ No. of good embryos } \\
\hline Pearson correlation & -0.12 & 0.03 & 0.20 & 1.00 & -0.10 & 0.19 & 0.03 & 0.04 \\
\hline Sig. (two-tailed) & 0.04 & 0.57 & 0.00 & & 0.09 & 0.00 & 0.61 & 0.54 \\
\hline \multicolumn{9}{|l|}{ No. of oocytes } \\
\hline Pearson correlation & 0.01 & -0.15 & -0.20 & -0.10 & 1.00 & 0.03 & -0.22 & -0.16 \\
\hline Sig. (two-tailed) & 0.85 & 0.01 & 0.00 & 0.09 & & 0.55 & 0.00 & 0.01 \\
\hline \multicolumn{9}{|l|}{ Clinical pregnancy } \\
\hline Pearson correlation & -0.15 & -0.03 & 0.08 & 0.19 & 0.03 & 1.00 & -0.04 & -0.01 \\
\hline Sig. (two-tailed) & 0.01 & 0.59 & 0.16 & 0.00 & 0.55 & & 50.45 & 0.80 \\
\hline \multicolumn{9}{|l|}{ Female age } \\
\hline Pearson correlation & 0.03 & 0.11 & 0.12 & 0.03 & -0.22 & -0.04 & 1.00 & 0.64 \\
\hline Sig. (two-tailed) & 0.64 & 0.06 & 0.04 & 0.61 & 0.00 & 0.45 & & 40.00 \\
\hline \multicolumn{9}{|l|}{ Male age } \\
\hline Pearson correlation & -0.06 & 0.04 & 0.08 & 0.04 & -0.16 & -0.01 & 0.64 & 1.00 \\
\hline Sig. (two-tailed) & 0.33 & 0.46 & 0.17 & 0.54 & 0.01 & 0.80 & 0.00 & \\
\hline
\end{tabular}

Correlations between the DNA fragmentation index (DFI) and fertilization rate (\%), no. of embryos cleaved (\%), no. of good quality embryos $(\%)$, no. of harvested oocytes, clinical pregnancy rate (\%), female age and male age in 302 IVF couples (first row). Correlations between each of the above two parameters are shown as well. All the percentage nos. have undergone arcsine transformation and square root changing.

differences in the above factors correlated to DFI between subgroups A, B and C in Groups 1 and 2. P-values $<0.05$ were considered to be statistically significant.

\section{Results}

Semen parameters and DNA fragmentation index values of patients. According to the DFI and semen parameters of each patient, we separated 302 IVF male partners into Groups 1 and 2, each group including the subgroups A, B and C. Based on prior experience (over 2000 patients tested using AO), we considered males with a DFI $<4 \%$ to be normal (subgroup A), those with a DFI of $4-10 \%$ to have moderate sperm DNA abnormality (subgroup B), and those with a DFI of $>10 \%$ to have serious sperm DNA abnormality (subgroup C). A summary of sperm test results for IVF and ICSI patients is listed in Table I. ICSI patients were not divided into subgroups due to their limited nos. Fluorescent imaging of representatives from each of the IVF subgroups (based on the DFI) is shown in Fig. 1.

Correlations between the DNA fragmentation index and various factors. The correlations between the DFI and various factors in IVF and ICSI patients are shown in Tables II and III. In the 302 couples undergoing IVF, the DFI was significantly correlated with the no. of good quality embryos $(\%)(\mathrm{r}=-0.12$, $\mathrm{P}<0.05)$ and with the clinical pregnancy rate $(\%)(\mathrm{r}=-0.15$, $\mathrm{P}<0.01)$. There were no significant correlations between the DFI and the other four parameters analyzed (fertilization rate $(\%)$, no. of embryos cleaved (\%), no. of harvested oocytes, female age and male age). Additionally, no significant correlations between the DFI and any parameters were found in the 67 ICSI couples. However, of note is the fact that in both IVF and ICSI couples the no. of harvested oocytes was signifi- 
Table III. Correlations between the DNA fragmentation index and various factors in intracytoplasmic sperm injection patients.

\begin{tabular}{|c|c|c|c|c|c|c|c|c|}
\hline & DFI & $\begin{array}{l}\text { Fertilization } \\
\text { rate }\end{array}$ & $\begin{array}{l}\text { No. of } \\
\text { embryos } \\
\text { cleaved }\end{array}$ & $\begin{array}{l}\text { No. of } \\
\text { good } \\
\text { embryos }\end{array}$ & $\begin{array}{l}\text { No. of } \\
\text { oocytes }\end{array}$ & $\begin{array}{c}\text { Clinical } \\
\text { pregnancy }\end{array}$ & $\begin{array}{l}\text { Female } \\
\text { age }\end{array}$ & $\begin{array}{c}\text { Male } \\
\text { age }\end{array}$ \\
\hline \multicolumn{9}{|l|}{ DFI } \\
\hline Pearson correlation & 1.00 & 0.06 & 0.01 & 0.02 & 0.09 & 0.15 & -0.03 & -0.16 \\
\hline Sig. (two-tailed) & & 0.62 & 0.94 & 0.86 & 0.48 & 0.23 & 0.80 & 0.18 \\
\hline \multicolumn{9}{|l|}{ Fertilization rate } \\
\hline Pearson correlation & 0.06 & 1.00 & -0.14 & -0.18 & -0.27 & -0.01 & 0.16 & 0.26 \\
\hline Sig. (two-tailed) & 0.62 & & 0.26 & 0.15 & 0.03 & 0.94 & 0.21 & 0.03 \\
\hline \multicolumn{9}{|l|}{ No. of embryos cleaved } \\
\hline Pearson correlation & 0.01 & -0.14 & 1.00 & 0.10 & -0.13 & 0.18 & 0.08 & 0.11 \\
\hline Sig. (two-tailed) & 0.94 & 0.26 & & 0.41 & 0.29 & 0.14 & 0.52 & 0.38 \\
\hline \multicolumn{9}{|l|}{ No. of good embryos } \\
\hline Pearson correlation & 0.02 & -0.18 & 0.10 & 1.00 & -0.12 & 0.06 & 0.03 & -0.01 \\
\hline Sig. (two-tailed) & 0.86 & 0.15 & 0.41 & & 0.34 & 0.62 & 0.81 & 0.93 \\
\hline \multicolumn{9}{|l|}{ No. of oocytes } \\
\hline Pearson correlation & 0.09 & -0.27 & -0.13 & -0.12 & 1.00 & 0.19 & -0.40 & -0.19 \\
\hline Sig. (two-tailed) & 0.48 & 0.03 & 0.29 & 0.34 & & 0.13 & 0.00 & 0.12 \\
\hline \multicolumn{9}{|l|}{ Clinical pregnancy } \\
\hline Pearson correlation & 0.15 & -0.01 & 0.18 & 0.06 & 0.19 & 1.00 & -0.07 & -0.14 \\
\hline Sig. (two-tailed) & 0.23 & 0.94 & 0.14 & 0.62 & 0.13 & & 0.57 & 0.27 \\
\hline \multicolumn{9}{|l|}{ Female age } \\
\hline Pearson correlation & -0.03 & 0.16 & 0.08 & 0.03 & -0.40 & -0.07 & 1.00 & 0.50 \\
\hline Sig. (two-tailed) & 0.80 & 0.21 & 0.52 & 0.81 & 0.00 & 0.57 & & 0.00 \\
\hline \multicolumn{9}{|l|}{ Male age } \\
\hline Pearson correlation & -0.16 & 0.26 & 0.11 & -0.01 & -0.19 & -0.14 & 0.50 & 1.00 \\
\hline Sig. (two-tailed) & 0.18 & 0.03 & 0.38 & 0.93 & 0.12 & 0.27 & 0.00 & \\
\hline
\end{tabular}

Correlations between the DNA fragmentation index (DFI) and fertilization rate (\%), no. of embryos cleaved (\%), no. of good quality embryos $(\%)$, no. of harvested oocytes, clinical pregnancy rate (\%), female age and male age in 67 ICSI couples (first row). Correlations between each of the above two parameters are shown as well. All the percentage nos. have undergone arcsine transformation and square root changing.

cantly correlated with fertilization rate $(\%)$ and female age. Furthermore, the ages of IVF and ICSI males and females were correlated with each other. In the IVF group, there were additional complicated relationships between the no. of embryos cleaved (\%), the no. of good quality embryos (\%), the no. of harvested oocytes, the clinical pregnancy rate $(\%)$, and female and male age.

Significant differences in four key factors between three different subgroups in IVF. Correlation analysis revealed that the DFI is somewhat related to the no. of good quality embryos $(\%)$ and the clinical pregnancy rate in IVF couples. To further explore the relationship between the DFI and IVF treatment outcome, we compared the fertilization rate, no. of embryos cleaved, no. of good quality embryos and clinical pregnancy rate in subgroups A, B and C (Table IV). This statistical analysis was performed separately in Groups 1 (normal semen) and 2 (abnormal semen). In Group 1, a significant difference between the A and B subgroups in terms of the no. of good quality embryos $(\mathrm{P}=0.015)$ and the clinical pregnancy rate $(\mathrm{P}=0.015)$ was revealed. Meanwhile, in Group 2 the fertilization rate $(\mathrm{P}=0.034)$ and the pregnancy rate $(\mathrm{P}=0.018)$ showed remarkable variations between subgroups $\mathrm{A}$ and $\mathrm{B}$.

\section{Discussion}

There is now some evidence to suggest that markers of sperm DNA integrity may be better measures of male fertility potential than conventional indicators. The study of sperm DNA damage is particularly relevant in an era when advanced forms of assisted reproductive technologies are frequently used. Many tests of sperm DNA damage are now available. In brief, the direct methods include: i) the deoxynucleotidyl transferase mediated dUTP nick end labeling (TUNEL) assay 
Table IV. Independent samples T test results for in vitro fertilization patients.

\begin{tabular}{|c|c|c|c|c|c|c|}
\hline \multirow[b]{2}{*}{ Subgroup } & \multicolumn{3}{|c|}{ Group 1 (normal) } & \multicolumn{3}{|c|}{ Group 2 (abnormal) } \\
\hline & A & $\mathrm{B}$ & $\mathrm{C}$ & A & B & $\mathrm{C}$ \\
\hline No. of patients & 99 & 82 & 19 & 40 & 50 & 12 \\
\hline \multicolumn{7}{|l|}{ Fertilization rate } \\
\hline Mean \pm SD & $0.994 \pm 0.251$ & $1.012 \pm 0.288$ & $0.998 \pm 0.263$ & $1.041 \pm 0.296$ & $0.913 \pm 0.269$ & $0.879 \pm 0.254$ \\
\hline P-value (subgroups) & $0.658(\mathrm{~A} \& \mathrm{~B})$ & $0.952(\mathrm{~A} \& \mathrm{C})$ & $0.847(\mathrm{~B} \& \mathrm{C})$ & $0.034(\mathrm{~A} \& \mathrm{~B})^{\mathrm{a}}$ & $0.093(\mathrm{~A} \& \mathrm{C})$ & $0.696(\mathrm{~B} \& \mathrm{C})$ \\
\hline \multicolumn{7}{|l|}{ No. of embryos cleaved } \\
\hline Mean \pm SD & $1.404 \pm 0.232$ & $1.359 \pm 0.241$ & $1.374 \pm 0.274$ & $1.486 \pm 0.176$ & $1.403 \pm 0.284$ & $1.500 \pm 0.163$ \\
\hline P-value (subgroups) & $0.658(\mathrm{~A} \& \mathrm{~B})$ & $0.611(\mathrm{~A} \& \mathrm{C})$ & $0.822(\mathrm{~B} \& \mathrm{C})$ & $0.111(\mathrm{~A} \& \mathrm{~B})$ & $0.803(\mathrm{~A} \& \mathrm{C})$ & $0.261(\mathrm{~B} \& \mathrm{C})$ \\
\hline \multicolumn{7}{|l|}{ No. of good embryos } \\
\hline Mean \pm SD & $0.696 \pm 0.447$ & $0.539 \pm 0.403$ & $0.636 \pm 0.470$ & $0.751 \pm 0.409$ & $0.606 \pm 0.452$ & $0.540 \pm 0.295$ \\
\hline P-value (subgroups) & $0.015(\mathrm{~A} \& \mathrm{~B})^{\mathrm{a}}$ & $0.594(\mathrm{~A} \& \mathrm{C})$ & $0.364(\mathrm{~B} \& \mathrm{C})$ & $0.120(\mathrm{~A} \& \mathrm{~B})$ & $0.104(\mathrm{~A} \& \mathrm{C})$ & $0.632(\mathrm{~B} \& \mathrm{C})$ \\
\hline \multicolumn{7}{|l|}{ Clinical pregnancy } \\
\hline Mean & 0.596 & 0.415 & 0.474 & 0.525 & 0.28 & 0.333 \\
\hline P-value (subgroups) & $0.015(\mathrm{~A} \& \mathrm{~B})^{\mathrm{a}}$ & $0.323(\mathrm{~A} \& \mathrm{C})$ & $0.639(\mathrm{~B} \& \mathrm{C})$ & $0.018(\mathrm{~A} \& \mathrm{~B})^{\mathrm{a}}$ & $0.094(\mathrm{~A} \& \mathrm{C})$ & $0.834(\mathrm{~B} \& \mathrm{C})$ \\
\hline
\end{tabular}

Comparison of independent samples T test results regarding fertilization rate (\%), no. of embryos cleaved (\%) and no. of good quality embryos $(\%)$ in the A, B and C subgroups was performed separately for Groups 1 and 2. All the percentage nos. have undergone arcsine transformation and square root changing. For clinical pregnancy, cross tabulation was applied to reveal differences between each subgroup in Groups 1 and 2. $\mathrm{P}$-values were calculated between pairs of subgroups as indicated in parentheses.

(12-15), ii) the single-cell gel electrophoresis (comet) assay (16-18), and iii) the in situ nick translation assay with or without sperm decondensation $(19,20)$. Indirect methods include: i) the acridine orange technique (AOT), first introduced by Teyada et al (10), and ii) sperm chromatin structure assay (SCSA) (21).

Both AOT and SCSA are used to measure the susceptibility of sperm DNA to acid-induced denaturation (22). Normal double-stranded DNA stains green and single-stranded DNA stains red in AOT (23), a simple microscopic procedure that comes with its own set of problems, while SCSA uses flow cytometry $(21,24)$. The percentage of DNA fragmentation, also referred to as the DNA fragmentation index (DFI), is derived from the ratio of red/red+green. AOT is therefore convenient and economical. Furthermore, as can be seen in Fig. 1., the distinction between normal and abnormal sperm is very clear and easy to determine.

With the advent of IVF and ICSI, concern over the use of damaged DNA is growing (25). It has been suggested that during natural fertilization only spermatozoa with enhanced DNA integrity, for example those that bind to oviduct (fallopian tube) cells and zona pelludia, are selected $(26,27)$. In contrast, assisted reproductive techniques (ARTs) bypass this selection process and may result in the inadvertent use of spermatozoa with damaged DNA. In the current study, statistical analysis indicated that the DFI is negatively correlated with the no. of good quality embryos and the clinical pregnancy rate (Table II). Although according to other reports there is no consistent relationship between sperm DNA damage and fertilization rates or early embryo development during IVF or
IVF/ICSI treatment, high levels of sperm DNA damage are inversely related to pregnancy rates in most, but not all, studies (28-36). As a result, the consistency between the findings of our study and others indicate that the testing of sperm DNA integrity by means of AOT should be encouraged.

The present study also combined routine semen analysis and DNA sperm integrity testing. Other studies have provided strong clinical evidence that the combination of increased sperm DNA damage with abnormalities in standard semen parameters can have an obvious impact on reproductive potential (34,37-39). Although many scientists have questioned the value of semen analysis in the clinical setting, it is essential for the identification of infertility and the diagnosis of disease severity (1).

Correlation analysis revealed that DFI values were negatively correlated with the no. of good quality embryos and the clinical pregnancy rate in IVF patients, which suggests the diagnostic capabilities of the DFI. When IVF patients were separated into two groups according to normal or abnormal semen results, the diagnostic potential of the DFI became even more apparent. There was a notable difference in clinical pregnancy rates between subgroup A (DFI <4\%) and B (DFI $4-10 \%$ ) in both groups, and the no. of good quality embryos and the fertilization rate were significantly different as well. Other factors related to clinical pregnancy did not show significant differences between different subgroups, but became unfavorable with an increase in DFI value, especially in subgroups A and B. However, in comparing patients with moderate-to-high DFI values (subgroup B) to those with higher DFI values (subgroup C), it was interesting to note that those 
in subgroup $\mathrm{C}$ did not have an increased possibility of failed IVF treatment. One reason for this may be the shortage of subjects in subgroup C. Another may be that the nature selection of zona pelludia or the technical process itself may enhance DNA integrity during fertilization, just like swim-up or density gradient centrifugation $(26,27)$.

It is well known that success rates in IVF depend on many factors, and vary as drastically as $0-50 \%$. However, reported IVF statistics provide little meaningful guidance for the individual patient hoping to achieve pregnancy with IVF. Our results provide additional information for predicting or explaining IVF outcomes. To summarize, even when semen results are abnormal, if the DFI value is very low it is probable that a successful pregnancy will be achieved. However, in cases with normal semen but a relatively higher DFI value, the outlook is not promising. As a result, the detection of damaged DNA in spermatozoa needs to be conducted along with standard semen analysis (12).

In this study, we did not observe any significant correlations between the DFI and various factors in ICSI couples. Previous studies have shown that there is no correlation between classical sperm parameters and the development potential of ICSI-derived embryos (9). It is well known that only motile sperm are used in ICSI. These, selected either by swim-up or density gradient centrifugation, have a significantly lower abnormal sperm DNA count than the sperm in semen $(29,40-42)$. This may explain why no relationship was found between abnormal sperm assessed in semen and fertilization and pregnancy rates in ICSI, and renders traditional testing of sperm DNA damage useless. $(36,43)$.

Last but not least, although the clinical indications of sperm DNA damage testing using AOT have been clarified in the present literature and by the several independent studies, concerns remain. According to most reporters, SCSA is reputed to have the strongest prognostic power $(1,4,44)$. Although AOT and SCSA are based on the same principles and use the same chromatin intercalating metachromatic AO dye, several differences between the two have been reported $(9,45)$. This in part explains why the average for abnormal DFI values in our study is much lower than than that achieved by ordinary evaluation. However, the AO test, particularly when used in combination with the microscopy method, is very convenient to perform. The combination of this test with routine semen analysis may provide additional information about the fertilizing ability of sperm. Higher DFI values with normal semen indicate a low possibility for success using IVF treatment, while lower DFI values, even with abnormal semen, suggest a greater chance of success.

\section{Acknowledgements}

This study was supported by the China National 973 Program (2006CB504002, 2006CB944005 and 2006CB944002)

\section{References}

1. Lewis SE: Is sperm evaluation useful in predicting human fertility? Reproduction 134: 31-40, 2007.

2. Nallella KP, Sharma RK, Aziz N and Agarwal A: Significance of sperm characteristics in the evaluation of male infertility. Fertil Steril 85: 629-634, 2006.
3. Tarozzi N, Bizzaro D, Flamigni C and Borini A: Clinical relevance of sperm DNA damage in assisted reproduction. Reprod Biomed Online 14: 746-757, 2007.

4. Lewis SE and Aitken RJ: DNA damage to spermatozoa has impacts on fertilization and pregnancy. Cell Tissue Res 322: 33-41, 2005

5. Morris ID, Ilott S, Dixon L and Brison DR: The spectrum of DNA damage in human sperm assessed by single cell gel electrophoresis (Comet assay) and its relationship to fertilization and embryo development. Hum Reprod 17: 990-998, 2002.

6. Bianchi PG, Manicardi GC, Bizzaro D, Bianchi U and Sakkas D: Effect of deoxyribonucleic acid protamination on fluorochrome staining and in situ nick-translation of murine and human mature spermatozoa. Biol Reprod 49: 1083-1088, 1993.

7. Evenson D and Wixon R: Meta-analysis of sperm DNA fragmentation using the sperm chromatin structure assay. Reprod Biomed Online 12: 466-472, 2006.

8. Cebesoy FB, Aydos $\mathrm{K}$ and Unlu C: Effect of sperm chromatin damage on fertilization ratio and embryo quality post-ICSI. Arch Androl 52: 397-402, 2006.

9. Virant-Klun I, Tomazevic T and Meden-Vrtovec H: Sperm singlestranded DNA, detected by acridine orange staining, reduces fertilization and quality of ICSI-derived embryos. J Assist Reprod Genet 19: 319-328, 2002.

10. Tejada RI, Mitchell JC, Norman A, Marik JJ and Friedman S: A test for the practical evaluation of male fertility by acridine orange (AO) fluorescence. Fertil Steril 42: 87-91, 1984.

11. Yun Q, Ting F, Chen J, et al: Pregnancies and births resulting from in vitro matured oocytes fertilized with testicular spermatozoa. J Assist Reprod Genet 22: 133-136, 2005.

12. Angelopoulou R, Plastira K and Msaouel P: Spermatozoal sensitive biomarkers to defective protaminosis and fragmented DNA. Reprod Biol Endocrinol 5: 36, 2007.

13. Sun JG, Jurisicova A and Casper RF: Detection of deoxyribonucleic acid fragmentation in human sperm: correlation with fertilization in vitro. Biol Reprod 56: 602-607, 1997.

14. Gorczyca W, Traganos F, Jesionowska H and Darzynkiewicz Z: Presence of DNA strand breaks and increased sensitivity of DNA in situ to denaturation in abnormal human sperm cells: analogy to apoptosis of somatic cells. Exp Cell Res 207: 202-205, 1993.

15. Sailer BL, Jost LK and Evenson DP: Mammalian sperm DNA susceptibility to in situ denaturation associated with the presence of DNA strand breaks as measured by the terminal deoxynucleotidyl transferase assay. J Androl 16: 80-87, 1995.

16. Anderson D, Dobrzynska MM and Basaran N: Effect of various genotoxins and reproductive toxins in human lymphocytes and sperm in the Comet assay. Teratog Carcinog Mutagen 17: 29-43, 1997.

17. Aravindan GR, Bjordahl J, Jost LK and Evenson DP: Susceptibility of human sperm to in situ DNA denaturation is strongly correlated with DNA strand breaks identified by single-cell electrophoresis. Exp Cell Res 236: 231-237, 1997.

18. Hughes CM, Lewis SE, Kelvey-Martin VJ and Thompson W: A comparison of baseline and induced DNA damage in human spermatozoa from fertile and infertile men, using a modified comet assay. Mol Hum Reprod 2: 613-619, 1996.

19. Twigg J, Fulton N, Gomez E, Irvine DS and Aitken RJ: Analysis of the impact of intracellular reactive oxygen species generation on the structural and functional integrity of human spermatozoa: lipid peroxidation, DNA fragmentation and effectiveness of antioxidants. Hum Reprod 13: 1429-1436, 1998.

20. Irvine DS, Twigg JP, Gordon EL, Fulton N, Milne PA and Aitken RJ: DNA integrity in human spermatozoa: relationships with semen quality. J Androl 21: 33-44, 2000

21. Evenson DP, Larson KL and Jost LK: Sperm chromatin structure assay: its clinical use for detecting sperm DNA fragmentation in male infertility and comparisons with other techniques. J Androl 23: $25-43,2002$.

22. Evenson DP and Wixon R: Clinical aspects of sperm DNA fragmentation detection and male infertility. Theriogenology 65 : 979-991, 2006.

23. Royere D, Hamamah S, Nicolle JC, Barthelemy C and Lansac J: Freezing and thawing alter chromatin stability of ejaculated human spermatozoa: fluorescence acridine orange staining and FeulgenDNA cytophotometric studies. Gamete Res 21: 51-57, 1988.

24. Evenson DP: Flow cytometry of acridine orange stained sperm is a rapid and practical method for monitoring occupational exposure to genotoxicants. Prog Clin Biol Res 207: 121-132, 1986.

25. Zini A and Libman J: Sperm DNA damage: clinical significance in the era of assisted reproduction. CMAJ 175: 495-500, 2006. 
26. Ellington JE, Evenson DP, Wright RW Jr, et al: Higher-quality human sperm in a sample selectively attach to oviduct (fallopian tube) epithelial cells in vitro. Fertil Steril 71: 924-929, 1999.

27. Liu DY and Baker HW: Human sperm bound to the zona pellucida have normal nuclear chromatin as assessed by acridine orange fluorescence. Hum Reprod 22: 1597-1602, 2007.

28. Lopes S, Sun JG, Jurisicova A, Meriano J and Casper RF: Sperm deoxyribonucleic acid fragmentation is increased in poor-quality semen samples and correlates with failed fertilization in intracytoplasmic sperm injection. Fertil Steril 69: 528-532, 1998.

29. Tomlinson MJ, Moffatt O, Manicardi GC, Bizzaro D, Afnan M and Sakkas D: Interrelationships between seminal parameters and sperm nuclear DNA damage before and after density gradient centrifugation: implications for assisted conception. Hum Reprod 16: $2160-2165,2001$.

30. Tomsu M, Sharma V and Miller D: Embryo quality and IVF treatment outcomes may correlate with different sperm comet assay parameters. Hum Reprod 17: 1856-1862, 2002.

31. Benchaib M, Braun V, Lornage J, et al: Sperm DNA fragmentation decreases the pregnancy rate in an assisted reproductive technique. Hum Reprod 18: 1023-1028, 2003.

32. Larson-Cook KL, Brannian JD, Hansen KA, Kasperson KM, Aamold ET and Evenson DP: Relationship between the outcomes of assisted reproductive techniques and sperm DNA fragmentation as measured by the sperm chromatin structure assay. Fertil Steril 80: 895-902, 2003.

33. Seli E, Gardner DK, Schoolcraft WB, Moffatt O and Sakkas D: Extent of nuclear DNA damage in ejaculated spermatozoa impacts on blastocyst development after in vitro fertilization. Fertil Steril 82: 378-383, 2004.

34. Virro MR, Larson-Cook KL and Evenson DP: Sperm chromatin structure assay (SCSA) parameters are related to fertilization, blastocyst development, and ongoing pregnancy in in vitro fertilization and intracytoplasmic sperm injection cycles. Fertil Steril 81: 1289-1295, 2004
35. Huang CC, Lin DP, Tsao HM, Cheng TC, Liu CH and Lee MS Sperm DNA fragmentation negatively correlates with velocity and fertilization rates but might not affect pregnancy rates. Fertil Steril 84: 130-140, 2005.

36. Zini A, Meriano J, Kader K, Jarvi K, Laskin CA and Cadesky K: Potential adverse effect of sperm DNA damage on embryo quality after ICSI. Hum Reprod 20: 3476-3480, 2005.

37. Henkel R, Hajimohammad M, Stalf T, et al: Influence of deoxyribonucleic acid damage on fertilization and pregnancy. Fertil Steril 81: 965-972, 2004.

38. Carrell DT, Liu L, Peterson CM, et al: Sperm DNA fragmentation is increased in couples with unexplained recurrent pregnancy loss. Arch Androl 49: 49-55, 2003.

39. Li Z, Wang L, Cai J and Huang H: Correlation of sperm DNA damage with IVF and ICSI outcomes: a systematic review and meta-analysis. J Assist Reprod Genet 23: 367-376, 2006.

40. Spano M, Cordelli E, Leter G, Lombardo F, Lenzi A and Gandini L: Nuclear chromatin variations in human spermatozoa undergoing swim-up and cryopreservation evaluated by the flow cytometric sperm chromatin structure assay. Mol Hum Reprod 5: 29-37, 1999.

41. Sakkas D, Manicardi GC, Tomlinson M, et al: The use of two density gradient centrifugation techniques and the swim-up method to separate spermatozoa with chromatin and nuclear DNA anomalies. Hum Reprod 15: 1112-1116, 2000.

42. Giwercman A, Richthoff J, Hjollund H, et al: Correlation between sperm motility and sperm chromatin structure assay parameters. Fertil Steril 80: 1404-1412, 2003.

43. Gandini L, Lombardo F, Paoli D, et al: Full-term pregnancies achieved with ICSI despite high levels of sperm chromatin damage. Hum Reprod 19: 1409-1417, 2004

44. Agarwal A and Said TM: Oxidative stress, DNA damage and apoptosis in male infertility: a clinical approach. BJU Int 95: 503-507, 2005.

45. Kosower NS, Katayose H and Yanagimachi R: Thiol-disulfide status and acridine orange fluorescence of mammalian sperm nuclei. J Androl 13: 342-348, 1992. 